\title{
VALOR ECONÔMICO AGREGADO POR HOSPITAIS UNIVERSITÁRIOS PÚBLICOS
}

ECONOMIC VALUE ADDED TO THE SOCIETY BY PUBLIC UNIVERSITY HOSPITALS

\section{RESUMO}

A crescente atuação da sociedade nos processos de discussão e de tomada de decisões relacionados com as políticas públicas incentiva a gestão pública no Brasil a buscar mecanismos para demonstrar eficiência na aplicação de recursos (accountability). Este trabalho teve como objetivo principal demonstrar como pode ser calculado o valor econômico agregado à sociedade por Hospitais Universitários Públicos. Para consecução desse propósito, conduziu-se um estudo de caso em um Hospital Universitário Público, avaliando seu desempenho econômico em um período de três anos. Este estudo revelou que o valor econômico agregado à sociedade no longo prazo pela entidade é positivo. Essa medida de valor proposta indicou que a sociedade está obtendo um retorno superior ao custo de oportunidade do capital investido, ou seja, o hospital está construindo valor econômico e, consequentemente, contribuindo para o bem-estar social.

\section{Carlos Alberto Grespan Bonacim}

Doutor em Controladoria e Contabilidade, Faculdade de Economia, Administração e Contabilidade, Universidade de São Paulo - SP, Brasil carlosbonacim@usp.br

\section{Adriana Maria Procópio de Araujo}

Professora da Faculdade de Economia, Administração e Contabilidade de Ribeirão Preto, Universidade de São Paulo - SP, Brasil

amprocop@usp.br

Recebido em 28.03.2008. Aprovado em 04.06.2009

Avaliado pelo sistema double blind review

Editores Científicos: Organizadores do Fórum

\begin{abstract}
The increasing participation of the society in the decision-making process related to public politics stimulates public administration in Brazil to search for mechanisms to demonstrate efficiency and disclosure in resource application. The main objective of this work is to calculate the economic value added to the society by Public University Hospitals. Therefore, a Public University Hospital case study has been carried out and its economic performance evaluated during a period of three years. This study has shown that the economic value added to the society in the long term by the entity is positive. The proposed value measurement has indicated that the society is getting a superior return from the opportunity costs of capital invested, that is, the hospital is constructing economic value and consequently contributing to the social welfare.
\end{abstract}

PALAVRAS-CHAVE Gestão hospitalar, gestão da saúde, resultado econômico da saúde, valor econômico agregado da saúde, bemestar social da saúde.

KEYWORDS Hospital management, health management, economic result of healthcare, healthcare economic value added, healthcare social welfare. 


\section{INTRODUÇÃO}

Desde a década de 1990, a gestão pública no Brasil está passando por grandes mudanças incentivadas por reivindicações sociais que pedem maior eficiência, transparência e eficácia na aplicação dos recursos públicos.

O Governo Federal (2004) define como serviços públicos essenciais: a seguridade social (previdência, assistência e saúde) e a educação. Esses serviços enquadram-se na dimensão estratégica social do plano de governo.

Evidentemente, discussões sobre a viabilidade financeira de Hospitais Universitários (HU) Públicos já vêm de longa data. Em especial, o atendimento com qualidade tem sido uma exigência crescente em qualquer tipo de serviço, inclusive para a área da saúde. Os pacientes têm demandado maiores níveis de desempenho da instituição que os atende.

Além disso, conforme Barbosa (1996), não existem instrumentos contratuais que estabeleçam claramente as prerrogativas, as obrigações, as metas e, muito menos, os critérios de avaliação do desempenho das políticas de saúde pública e de prestação de contas. Por isso, devemse empenhar esforços para desenvolver pesquisas sobre a avaliação do retorno desse investimento.

Tais instituições, por sua vez, devem "responder" a seus pacientes (usuários) com um atendimento qualificado, envolvendo questões como tempo de espera, segurança do paciente e do trabalhador, além da confiabilidade.

Nesse ambiente, discussões acerca de condutas e procedimentos merecem destaque entre os dirigentes de organizações, os profissionais da área da saúde e fundamentalmente o meio acadêmico: Bittar (1996), Marinho (1998), Lima-Gonçalves e Aché (1999), Malik e Teles (2001) e Cherchiglia e Dallari (2006), entre outras pesquisas.

Nos Hospitais Universitários, essas questões aparecem com nível de complexidade acentuado. Além da prestação da assistência médica, essas entidades agregam atividades de ensino e pesquisa e, ainda, devem ser um referencial em tecnologia de ponta.

Sendo assim, os HU têm diante de si o desafio de prover atenção à saúde de uma crescente população idosa e arcar com os custos dela derivados (DANIELS, 1982), equacionando a relação entre disponibilidade de serviços e acesso versus financiamento adequado. Cabe ainda aos gestores prestar contas ao governo e à sociedade sobre a utilização dos recursos públicos.

Estas constituem algumas das justificativas para a realização de um estudo, com enfoque no cálculo do valor agregado à sociedade pelas decisões operacionais e financeiras e seus direcionadores de valor.
Selecionou-se, por conveniência, o Hospital das Clínicas da Faculdade de Medicina de Ribeirão Preto da Universidade de São Paulo (HCFMRP-USP), para conhecer a realidade de um hospital universitário público sob o prisma da Gestão Baseada em Valor (GBV).

Por isso, a pesquisa procura acompanhar o que existe na gestão contemporânea de empresas, efetuando a devida adequação às condições das entidades públicas. Nesse contexto, a adaptação da teoria de GBV pode representar uma ferramenta para a prática gerencial de avaliação do desempenho de empresas públicas, em especial dos Hospitais.

Considerando o interesse em contribuir para a melhoria do processo de gestão de avaliação de investimentos realizados pela sociedade (Estado) em hospitais universitários públicos, pretende-se, com esse estudo, responder à seguinte questão orientadora de pesquisa: como apurar o valor econômico agregado à sociedade por Hospitais Universitários Públicos?

Assim, em consonância com a questão estabelecida, o objetivo geral deste trabalho é: demonstrar como pode ser mensurado o valor econômico agregado à sociedade por Hospitais Universitários Públicos.

\section{REFERENCIAL TEÓRICO}

Este tópico realiza uma compilação da literatura existente sobre os hospitais universitários, abordando o seu papel, as suas características e obstáculos mais comuns enfrentados por essas entidades. Discute também, a compatibilidade da Gestão Baseada em Valor (GBV) com as organizações públicas, com vistas a possibilitar o desenvolvimento de um instrumento de avaliação que inicialmente foi desenvolvido para empresas privadas.

\section{Caracterização dos hospitais universitários públicos}

Os Hospitais Universitários (HU) caracterizam-se como centros de saúde públicos vinculados a cursos de graduação em medicina. São conhecidos como hospitaisescolas, pois servem de laboratórios para os estudantes. Alguns são extremamente conceituados e oferecem tratamento de alta qualidade sem qualquer custo para o paciente.

Campos (1999), Cordeiro (2001) e Matos e Pompeu (2003), nos estudos em Saúde Pública, categorizam os hospitais em: (i) públicos municipais, estaduais e federais (com capital e recursos estatais); (ii) privados (contratados e de entidades de classe); e (iii) universitários (ensino e pesquisa). 
Para Medici (2001) um Hospital Universitário é entendido, antes de tudo, como um centro de atenção médica de alta complexidade, pois: (i) tem importante papel no atendimento médico de alta complexidade; (ii) apresenta forte envolvimento em atividades de ensino e pesquisa relacionada ao tipo de atendimento médico dispensado; (iii) atrai alta concentração de recursos físicos, humanos e financeiros em saúde; (iv) exerce um papel político importante na comunidade que está inserido, dada sua escala, dimensionamento, orçamento e custos.

As características dos HU fazem com que seus custos sejam ainda mais elevados, quando comparados a hospitais não-universitários de alta tecnologia, tais como: atividades docente-assistenciais e serviços básicos de saúde, quando sua estrutura é constituída para oferecer atividades de alta tecnologia.

Em 2001, esses hospitais universitários públicos foram responsáveis por aproximadamente $9 \%$ dos leitos, $12 \%$ das internações e 24\% dos recursos do Sistema Único de Saúde (SUS) destinados ao pagamento de internações. Conforme Albano (2002), responderam, no mesmo período, por cerca de $50 \%$ das cirurgias cardíacas, $70 \%$ dos transplantes, $50 \%$ das neurocirurgias e $65 \%$ dos atendimentos na área de malformações craniofaciais. Tal concentração reflete maior dimensão média, e envolvimento significativo com a alta complexidade, segundo HOSPITAIS (2002).

Todavia, conforme Silva e outros (2003), os hospitais de ensino encontram-se debilitados por serem mais dispendiosos, dado que incorporam atividades de ensino, pesquisa e extensão e por serem um referencial em tecnologia de ponta quando é crescente a exigência do governo e da sociedade pela racionalização dos gastos e despesas.

Para que os HU possam fazer tais investimentos é importante que haja recursos. Eles têm basicamente duas maneiras de acumular recursos: (i) gastar menos do que ganham, isto é, acumular lucro ou superávit; (ii) conseguir recursos extras do governo através da aprovação de projetos.

A condição de lucro ou superávit é alcançada quando as receitas superam os gastos (ASSAF NETO, 2003). Especificamente, quando o repasse (no âmbito público, por exemplo, ressarcimento via convênio com o SUS e demais subvenções do Estado) aos HU é suficiente para quitar os compromissos financeiros e, ainda, proporciona sobra de caixa. Nessa condição, há uma oportunidade para o redirecionamento dos recursos para investimentos.

A outra forma implica a obtenção de recursos para investimento por meio de verbas extras do Governo, através da aprovação de projetos específicos - normalmente, autorizados a partir de créditos orçamentários suplementares
(SLOMSKI, 2003). Por exemplo, projetos de expansão ou de recuperação de unidades ambulatoriais, centros cirúrgicos podem ser desenvolvidos por meio de dotação orçamentária adicional ou suplementar, se for o caso.

\section{UMA CONTEXTUALIZACCÃO DOS HOSPITAIS UNIVERSITÁRIOS PÚBLICOS NO SISTEMA ÚNICO DE SAÚDE (SUS)}

Para mensurar o valor econômico agregado à sociedade, por Hospitais Universitários Públicos, é fundamental contextualizar e entender esse setor, em especial, discutir o papel dos Hospitais Universitários Públicos no Sistema Único de Saúde (SUS).

Nesse contexto, o enfraquecimento da seguridade social na América Latina (o que inclui a realidade brasileira), conforme Leeder (1992), Vergara (2000) e Cordeiro (2001), proporcionou dificuldades associadas à manutenção dessas instituições, impedindo que os HU exerçam plenamente suas funções primordiais: a atenção à saúde da comunidade (BOSSERT; LARRANAGA; RUIZ MEIR, 2000), a formação de profissionais, a produção de conhecimento e o desenvolvimento tecnologia para a área da saúde.

A consequência imediata desse enfraquecimento seria um aumento da participação de recursos da iniciativa privada, criando instituições de economia mista (parte do capital público, parte privado) tal como ocorreu em outros setores, como de telecomunicações, energia elétrica etc., antes do fenômeno das privatizações.

Entretanto, no setor da saúde brasileiro, a iniciativa privada não ocupou esse espaço deixado pelo Estado. Conforme o panorama setorial divulgado na Gazeta Mercantil, "os hospitais privados conveniados ao Sistema Único de Saúde (SUS) vêm perdendo espaço nos últimos anos dez anos. Em contrapartida, os hospitais públicos, especialmente os universitários, estão avançando" ( $\mathrm{O}$ MAPA, 2006, p. A-10).

O MAPA (2006) acrescenta que em 1992, 46,70\% dos hospitais integrados ao SUS eram de natureza particular, ou seja, praticamente metade dos convênios de prestação de serviços assistenciais do SUS estava estabelecida com hospitais privados. Em 2003, esse percentual caiu para $30,46 \%$. Essa redução de $16,24 \%$ representa uma demanda potencial para os hospitais públicos, em especial os universitários, no caso dos atendimentos mais complexos.

Conforme mencionado anteriormente, a lógica seria que a iniciativa privada "ocupasse" com eficiência o espaço deixado pelo Estado. Dessa forma, sendo eficientes, 
os hospitais privados conseguiriam ser viáveis economicamente, mesmo custeados pelo SUS.

Entretanto, o que se verificou foi uma redução na participação de hospitais privados conveniados, ou seja, uma "falta de interesse" do capital privado - panorama observado por Carr-Hill (1989), mas tendo como objeto o método RAWP (Resource Allocation Working Party) da Grã-Bretanha, 1976 - necessidades regionais.

Matos e Pompeu (2003, p. 630) explicam o porquê dessa "falta de interesse" dos investimentos de iniciativa privada para com o setor de saúde, ao apresentarem uma "análise da relação entre os prestadores privados de serviços de saúde e o SUS", em que demonstram os reflexos da reestruturação da rede hospitalar brasileira na década de 1990.

$\mathrm{Na}$ década de 1990, aproximadamente 10,50\% dos hospitais privados romperam o contrato com o SUS, com a justificativa de que os recursos repassados pelo Estado eram insuficientes para a manutenção de suas atividades e que, portanto, inviabilizariam a prestação dos serviços.

Em especial os hospitais públicos, pois, em tese, foi a rede hospitalar exclusivamente pública que absorveu a demanda repelida $(10,50 \%)$ pelos hospitais particulares. O resultado prático disso são as filas intermináveis, a precariedade nos atendimentos e nas condições de trabalho dos profissionais dessas instituições etc.

Além disso, considerando-se que nesse mesmo período (1992 a 2003) os investimentos nos hospitais permaneceram constantes (representam 12\% dos recursos do da Seguridade Social, conforme HOSPITAIS, 2002), a precariedade da situação financeira dessas organizações só se agravou: crise financeira, atrasos nos pagamentos de funcionários e fornecedores (JARLIER; CHARVETPROTAT, 2000).

Essencialmente, o papel dos HU não se restringe à prestação de serviços assistenciais (ou de saúde curativa). Esses hospitais contribuem para a formação de estudantes da área de saúde de nível superior, além de sediar muitos cursos de pós-graduação em senso estrito e amplo. Assim sendo, o principal objetivo dos HU está voltado para as atividades de ensino-pesquisa: a formação de profissionais em saúde e a geração de conhecimento.

Segundo Portela e outros (2004), todas essas atribuições fazem com que os custos dos HU sejam ainda mais elevados, quando comparados a hospitais não universitários de alta tecnologia. Tais atividades (de ensino-pesquisa) são onerosas e contribuem para que os HU passem por uma crise financeira crônica.

Esses problemas são potencializados nos $\mathrm{HU}$, os quais dificilmente poderiam ser competitivos em um sistema de reembolso por serviço e seriam pouco atrativos aos planos de seguro médico. A tendência é que se mantenham custeados pelo setor público, com boa parte dos serviços prestados de forma gratuita ou subsidiados (MEDICI, 2001).

Contudo, existe ainda um ponto importante, salientado por Cecílio (1999): a inexistência de pressão social suficiente para obrigar os hospitais a se preocuparem com os indicadores que apresentam de diversas naturezas, em especial econômica, legitimidade, inércia, "falta de vontade" de pensar em mudar tanto a organização quanto sua cultura (MALIK, 1992).

Conforme Lima-Gonçalves (1998), atualmente, exigese de um "hospital moderno" o desenvolvimento de programas e outras atividades que contribuem para a elevação do padrão de saúde da população: promoção da saúde e prevenção da doença, normalmente de elevada eficiência e de alta contribuição para a saúde da população.

\section{VALOR ECONÔMICO AGREGADO POR ENTIDADES PÚBLICAS COM CÁLCULO FUNDAMENTADO NOS PRECEITOS DA GESTÃO BASEADA EM VALOR}

No contexto empresarial, os gestores executam as políticas definidas pelos "donos do capital" (acionistas, normalmente), a quem devem prestar contas. Existe, portanto, certa analogia nessa relação de accountability entre esses dois ambientes: empresarial (privado) e público.

Ressalta-se o conceito de accountability adotado neste estudo: prestação de contas por meio de instrumentos que facilitem a transparência: "(...) relatórios que façam com que o cidadão possa fazer comparações com resultados privados e, assim, sentir-se confortável ao ver que a gestão pública está sendo eficiente no gasto dos recursos públicos" (SLOMSKI, 2005, p. 133).

Assim, pretende-se contextualizar a avaliação de desempenho de entidades públicas de forma geral, bem como apresentar algumas proposições sobre avaliação de desempenho, contempladas na literatura, inicialmente voltadas para o setor privado (Valor Econômico Agregado ou EVA ${ }^{\circledR}$ ), mas que podem ser perfeitamente aplicadas às organizações públicas, especificamente aos HU Públicos.

\section{Avaliação de desempenho econômico em entidades públicas: considerações preliminares}

Para Olak (2000, p. 110), uma avaliação de desempenho deve ter indicadores que meçam, entre outras coisas: (i) eficácia: em que grau o produto (ou serviço, no caso dos hospitais) atende aos padrões estabelecidos consideradas as demandas de usuários e clientes; (ii) eficiência: em que 
grau o produto (ou serviço) está sendo produzido a um custo mínimo; e (iii) qualidade: em que grau o produto (ou serviço) é adequado ao uso pelo usuário (cliente ou cidadão).

Nesse sentido, inexistem quaisquer diferenças entre o processo de avaliação de desempenho entre as empresas do setor privado e os demais - organizações públicas, sem fins lucrativos. Em uma analogia, no setor privado, os acionistas usam os dados financeiros e econômicos (eficiência) publicados pela empresa para avaliar sua situação financeira e decidir se compram, vendem ou mantêm suas ações.

O cidadão era visto (até então) pelo setor público como apenas um contribuinte, o equivalente a um cliente no setor privado. Ele (cidadão), não necessitava de uma detalhada prestação de contas. Para isso, Slomski (2005, p. 96) coloca o contribuinte como o acionista da "coisa pública". Isso significa que a entidade pública deve prestar contas à sociedade, tal qual empresas privadas devem prestar contas para o acionista.

Assim, quando se pensa em calcular o valor econômico agregado por uma entidade pública, deve-se pensar no valor adicionado para a sociedade, ou seja, deve-se calcular a quantidade de valor econômico que a entidade agrega à sociedade.

\section{PROCEDIMENTOS METODOLÓGICOS}

Considerou-se a condução do estudo de caso como a parte empírica do trabalho, com a utilidade de testar as adaptações da teoria de GBV para aplicação em entidades públicas, bem como demonstrar uma maneira de calcular o valor econômico agregado à sociedade por essas entidades.

De acordo com Yin (2005), o estudo de caso é uma pesquisa empírica que investiga um fenômeno contemporâneo dentro de um contexto real, quando os limites entre fenômeno e contexto não são claramente definidos, e na qual múltiplas fontes de evidências são usadas. Martins e Theóphilo (2007) definem estudo de caso como uma estratégia de pesquisa caracterizada pela análise profunda e intensa de uma unidade social que pede avaliação qualitativa.

Este estudo de caso contemplou uma análise das receitas econômicas do hospital universitário público estudado no período de 2003 a 2005.

Além disso, o escopo dessa pesquisa foi o cálculo do valor agregado à sociedade por um hospital universitário público brasileiro, por meio de sua prestação de serviços assistenciais. Dessa maneira, o cálculo não abrangeu a re- ceita econômica advinda das atividades de ensino-pesquisa também executadas por essa entidade.

Para coletar os dados, três métodos foram adotados, conforme sugere a estratégia do estudo de caso (triangulação dos dados): análise documental, entrevista e observação direta. Na análise documental, as demonstrações contábeis da instituição, bem como as planilhas de custos, planilhas de faturamento e as tabelas de preços referenciais da área foram estudadas, conforme Martins e Theóphilo (2007).

Além disso, entrevistou-se (por meio de entrevista não estruturada) os responsáveis das áreas: assessoria técnica, grupo de avaliação de desempenho e seção de custos, áreas responsáveis pela criação, mensuração e gestão dos indicadores de desempenho. A observação direta deu-se por um dos autores em trabalho temporário realizado na organização. Os aspectos relacionados ao cálculo do o valor econômico agregado à sociedade são detalhados a seguir

\section{Desenvolvimento do indicador de valor econômico agregado por entidades públicas com cálculo fundamentado nos preceitos da Gestão Baseada em Valor (GBV)}

As empresas privadas calculam o valor econômico agregado a seus acionistas de diversas formas. Uma delas, bastante consolidada no meio empresarial, é por meio do indicador financeiro: Valor Econômico Agregado $\left(\mathrm{EVA}^{\circledR}\right)$. Nesse contexto, faz-se a adaptação da metodologia de cálculo do $\mathrm{EVA}^{\circledR}$.

É importante considerar que o lucro residual abordado no modelo do $\mathrm{EVA}^{\oplus}$ significa que a riqueza de uma companhia só começa a existir a partir do momento em que a empresa remunerou o capital nela investido. A mensuração do retorno econômico (EVA $\left.{ }^{\circledR}\right)$ é expressa no Quadro 1.

Quadro 1 - Expressão da mensuração do retorno econômico (EVA $\left.{ }^{\oplus}\right)$

$$
E V A^{\oplus}=\text { LOP }-(\text { CMPC } \times \text { INV })
$$

Fonte: ASSAF NETO, 2003

Com o intuito de adaptá-los às entidades públicas, cada um desses fatores (LOP, CMPC e INV) é analisado isoladamente, desenvolvendo os indicadores sintetizados no Quadro 2: (i) valor econômico agregado de curto prazo (VECP); e (ii) valor econômico agregado para a sociedade (VEAS) - longo prazo.

Inicialmente, o lucro operacional (LOP), que é o resultado das decisões de investimento da empresa. Ou ainda, é o resultado produzido pela atividade fim da empresa. 
De forma simplificada, pode ser entendido também como a diferença entre as receitas e as despesas operacionais.

No caso da entidade pública, também é possível encontrar o 'lucro operacional'. Basicamente, seria a diferença entre a receita pública (receita econômica) e os custos (e despesas) operacionais na prestação do serviço público. Especificamente, nas entidades públicas, existem os termos superávits e déficits.

Segundo Slomski (2005), os termos lucro e superávit ou prejuízo e déficits não são comparáveis, cada qual tem seu significado: "lucro representa eficácia na empresa privada, superávit é o indicador de economia de recursos" (SLOMSKI, 2005, p. 99).

Contudo, o conceito de receita para as entidades privadas não é o mesmo daquele utilizado na contabilidade pública ou nos indicadores de desempenho tradicionais (BARROW, WAGSTAFF, 1989).

A receita contábil na entidade privada normalmente é o valor oferecido em contrapartida do bem ou serviço. $\mathrm{Na}$ entidade pública, o valor oferecido em contrapartida do bem oferecido não é contabilizado. Conforme Slomski (1996), a receita pública não reflete o valor que o consumidor estaria disposto a pagar pelo bem ou serviço oferecido.

O autor vai além e propõe o cálculo do resultado econômico da entidade pública, utilizando o conceito de receita da entidade privada. Para ele, o resultado econômico da entidade pública é a diferença entre a receita econômica e a soma dos custos diretos e indiretos identificáveis à área de responsabilidade que produziu tal receita (SLOMSKI, 1996, p. 56).

A receita econômica, por sua vez, "é o produto da multiplicação do custo de oportunidade que o cidadão desprezou ao utilizar o serviço público, pelos serviços que ele efetivamente tenha executado" (SLOMSKI, 1996, p. 53).

Como custo de oportunidade o autor entende "o menor preço de mercado a vista atribuído ao serviço prestado ao cidadão com similar qualidade, oportunidade e tempestividades daquele desprezado por ele ao utilizar o serviço público" (SLOMSKI, 1996, p. 54).

Assim, para o caso dos $\mathrm{HU}$, a receita econômica de um período representa o menor preço de mercado que um paciente pagaria para obter os serviços de saúde oferecidos, no mesmo período.

Observando a realidade do setor, o serviço de menor preço com qualidade similar seria o oferecido pelos planos de saúde. Como os planos de saúde geralmente utilizam a tabela de preços-padrão para os diversos tipos de serviços elaborados pela Associação Médica Brasileira (AMB), ela representa a referência (neste trabalho) para o cálculo da receita econômica do caso do Hospital Universitário Público.

Contudo, é importante considerar que o consumidor de saúde (no caso o usuário) não tem opção de não adquirir ou não, o bem ou o serviço oferecido. Para Magalhães Jr. (2006, p. 40), nos sistemas de saúde em geral, a forte regulação do Estado representa "(...) uma das maneiras de correção das chamadas imperfeições de mercado".

Adicionalmente, para Malta e outros (2004) e Santos e Merhy (2006) essa condição traz reflexos na prestação de serviços (essencialmente na produtividade das estruturas) e na equidade social, que deve se traduzir no acesso aos cuidados e em uma repartição geográfica equitativa.

O conceito do lucro operacional dos HU é, então, definido pela diferença entre a receita econômica (quantidade de serviços prestados multiplicado pelos respectivos valores da tabela AMB) e os custos (e despesas) incorridos para oferecer o serviço ao usuário. Define-se assim, o segundo componente para o cálculo do $\mathrm{EVA}^{\circledR}$ dos hospitais universitários.

O próximo componente do $\mathrm{EVA}^{\circledR}$ a definir é o Custo Médio Ponderado do Capital (CMPC). Deve-se observar como o Estado investiria o recurso se não o destinasse aos HU. Baseado no conceito de custo de oportunidade, propõe-se o uso da taxa básica de juros da economia brasileira determinada pelo Sistema Especial de Liquidação e de Custodia (SELIC).

Contudo, o ideal seria o desenvolvimento de estudo para buscar uma taxa que realmente reflita o custo de capital dos hospitais baseado no modelo de precificação de ativos (Capital Asset Pricing Model - CAPM), inclusive com a tentativa de desenvolvimento do fator de risco, denominado beta ( $\beta$ ). Porém, esse estudo adota a taxa a premissa de que a taxa SELIC representa o custo de Capital para o Estado de forma pertinente.

O último componente do $E A^{\circledR}$ a ser definido é o valor do investimento (INV). De acordo com a teoria da Gestão Baseada em Valor, o investimento é dado pela soma do patrimônio líquido com o passivo oneroso da instituição. No caso dos hospitais universitários, enquanto entidade pública, o patrimônio social acumula o investimento do Estado realizado diretamente no ativo permanente da organização e o superávit/ déficit acumulado.

Assim, há duas possibilidades: (i) utilizar o gasto do Estado no período, ou seja, todo o investimento feito pelo Estado no HU em determinado ano, resultando no valor agregado pela entidade na prestação do serviço público por período; e (ii) utilizar o valor do passivo oneroso somado ao patrimônio social, como é proposto no $\mathrm{EVA}^{\circledR}$ original.

O Quadro 2 mostra um resumo das medidas propostas no estudo. Confirma-se então a possibilidade de adaptar o EVA $^{\circledR}$ para as entidades públicas, inclusive do setor hospitalar. 
Como as duas possibilidades geram valores diferentes e com significados diferentes, a proposta deste estudo é adotar os dois valores como indicadores de desempenho. $\mathrm{O}$ resultado originado da primeira possibilidade (gasto do Estado no período) é o valor econômico agregado de curto prazo (VECP). Representa o quanto a sociedade ganha (ou perde) no período por "terceirizar" (delegar uma obrigação do Estado para terceiros) a prestação de um serviço para uma entidade isolada.

O segundo resultado é o valor econômico agregado para a sociedade (VEAS), isto é, representa o valor devolvido para a sociedade por ela "deixar" o capital investido na entidade.

As medidas de valor desenvolvidas neste trabalho, e apresentadas no Quadro 2, representam uma importante contribuição enquanto ferramentas de avaliação de desempenho pelo fato de incorporarem o conceito de custo de oportunidade. Elas permitem uma análise mais segura do "quanto" do investimento público é devolvido para a sociedade.
Tais medidas de valor econômico demonstram o potencial das entidades públicas na prestação de serviço que agregue valor, tal qual serviço privado, pois as medidas de avaliação de desempenho convencionais (lucro e suas variações) não consideram o custo de oportunidade do capital investido, sendo para as entidades públicas a taxa SELIC. Quando o governo altera o valor da taxa SELIC, automaticamente afeta o custo do capital a ele confiado pela sociedade. As medidas de valor VECP e VEAS têm a sensibilidade de demonstrar os impactos proporcionados pelas políticas econômicas no valor econômico agregado pelas entidades públicas.

Assim, um aumento na taxa básica de juros aumenta o custo de oportunidade do capital investido pela sociedade, exigindo maior eficiência operacional (medida pelo Resultado Econômico Operacional) das entidades públicas, como acontece no setor privado.

Portanto, quando o valor apurado pelas medidas VECP e VEAS é positivo "(...) significa que o agenciamento está sendo a um custo menor que o preço de mercado"

Quadro 2 - Medidas de cálculo do valor agregado para a entidade pública

\begin{tabular}{|c|c|}
\hline MEDIDA DE VALOR & METODOLOGIA DE CÁLCULO \\
\hline $\begin{array}{l}\text { Valor Econômico Agregado } \\
\text { de Curto Prazo (VECP) }\end{array}$ & $\begin{array}{c}\text { Receita Econômica } \\
\text { (-) Custos Operacionais } \\
(-) \text { Despesas Operacionais } \\
\text { (=) Resultado Econômico Operacional } \\
\text { Taxa SELIC } \\
\text { (x) Investimento feito pelo governo na entidade no período } \\
(=) \text { Custo de oportunidade do capital do Estado } \\
\text { Resultado Econômico Operacional } \\
\text { (-) Custo de oportunidade do capital do Estado } \\
\text { (=) Valor Econômico Agregado de Curto Prazo (VECP) }\end{array}$ \\
\hline $\begin{array}{l}\text { Valor Econômico Agregado } \\
\text { para a Sociedade (VEAS) }\end{array}$ & $\begin{array}{c}\text { Receita Econômica } \\
\text { (-) Custos Operacionais } \\
(-) \text { Despesas Operacionais } \\
(=) \text { Resultado Econômico Operacional } \\
\text { Taxa SELIC } \\
\text { (x) Investimento total feito na entidade (Passivo oneroso + PS) } \\
(=) \text { Custo de oportunidade para a Sociedade } \\
\text { Resultado Econômico Operacional } \\
\text { (-) Custo de oportunidade para a Sociedade } \\
\text { (=) Valor Econômico Agregado para a Sociedade (VEAS) }\end{array}$ \\
\hline
\end{tabular}


(SLOMSKI, 2005, p. 100), remunerando inclusive o custo de oportunidade do capital investido pela sociedade. Ou seja, a entidade é eficiente na prestação de serviços à comunidade, tendo como base preços de mercado (benchmarking).

Por outro lado, no caso de valores negativos para VECP e VEAS, trata-se de algo equivalente a um "(...) prejuízo econômico, a sociedade poderá rever toda estrutura de agenciamento" (SLOMSKI, 2005, p. 100). Isso significa dizer que a sociedade não deve continuar "terceirizando" a prestação de serviço público.

Não restam dúvidas de que as medidas VECP e VEAS são úteis e válidas. No entanto, a utilização delas deve superar os desafios impostos pelos requisitos para sua implantação: pode-se prever que haverá dificuldades semelhantes com as encontradas pelas empresas privadas quando da adoção do $\mathrm{EVA}^{\circledast}$, por exemplo, a adequação do sistema de informações.

Ressalta-se que a proposta desta pesquisa corrobora com as reflexões do estudo de Machado e Kuchenbercker (2007), essencialmente acerca da importância do fortalecimento da sustentabilidade organizacional dos HU, sobretudo em relação a gestão financeira e de indicadores, além da incorporação de aspectos ligados à qualidade dos serviços prestados, à transparência (accountability) e à responsabilidade social.

\section{ESTUDO EMPÍRICO: 0 CÁLCULO DO VALOR ECONÔMICO AGREGADO À SOCIEDADE POR UM HOSPITAL UNIVERSITÁRIO PÚBLICO}

Este tópico aplica os conceitos discutidos (na revisão bibliográfica) ao hospital objeto de estudo neste artigo. Em primeiro lugar, há uma caracterização do hospital e em seguida demonstra-se o cálculo do valor econômico e analisam-se os resultados encontrados.

\section{Unidade de análise: o Hospital Universitário Público}

O Hospital Universitário Público objeto de análise (HCFMRP-USP) é vinculado à Secretaria da Saúde do Estado de São Paulo e associado à Faculdade de Medicina de Ribeirão Preto da Universidade de São Paulo para fins de ensino, pesquisa e prestação de serviços médico-hospitalares à comunidade. Constitui-se centro de referência em tratamentos de alta complexidade e é integrado ao SUS. Possui, atualmente, 843 leitos, 34 salas cirúrgicas, 333 salas de atendimento ambulatorial dispostos em duas unidades: HC Campus e Unidade de Emergência, num total de $137.668,58 \mathrm{~m}^{2}$.
Presta serviços médico-hospitalares, de urgência e tratamentos específicos de alta complexidade e tecnologia de ponta à população e à toda a região, ultrapassando inclusive os limites do Estado de São Paulo, com recursos provenientes do Tesouro do Estado e da arrecadação SUS, esta última repassada através de sua Fundação (direito privado com autonomia administrativa): Fundação de Apoio ao Ensino, Pesquisa e Assistência do HCFMRPUSP (FAEPA).

\section{Cálculo do VECP e do VEAS e análise dos resultados}

Para calcular o valor econômico do HU Público, foram observados todos os pontos discutidos na revisão bibliográfica deste trabalho. Assim, o único a ser detalhado é o valor da receita econômica, visto que o custo de capital e os valores de investimento foram discutidos anteriormente. Por fim, serão analisados os resultados encontrados.

Conforme sugerido na revisão bibliográfica, o cálculo da receita econômica deverá ser a quantidade de serviços prestados multiplicada pelos respectivos valores da tabela AMB. Entretanto, o HU Público presta serviços também através da Fundação, para convênios particulares. Para essa prestação de serviços a Fundação do HU elaborou uma tabela de preços baseada na tabela AMB.

Optou-se pela utilização dos valores praticados na tabela da Fundação, uma vez que esta utiliza a infraestrutura do HU Público, isto é, a qualidade do serviço prestado no HU Público e na Fundação é similar e, portanto, comparável (como propõe Slomski, 1996, com o conceito de custo de oportunidade).

A Tabela 1 evidencia uma diferença significativa entre os valores referenciais do SUS e de sua Fundação, ou mercado. Entretanto, essa análise preliminar não é suficiente. Antes da aplicação de um teste de igualdade de médias (como recomenda a literatura), realizou-se o teste de Komolgorov-Smirnov para testar a normalidade da população, isto é, se os valores apresentados na amostra têm distribuição normal ou não.

O teste de Komolgorov-Smirnov (Tabela 2) apontou uma distribuição normal.

Por isso, investigou-se se a diferença entre os valores "SUS" e de "Mercado" era estatisticamente significante para dar maior confiabilidade às medidas de valor (VECP e VEAS) desenvolvidas neste estudo (valor econômico agregado à sociedade). Para tanto, aplica-se um teste para realizar inferências a partir dessas duas amostras.

Dessa forma, optou-se pela utilização do modelo paramétrico para o teste de diferença de médias no Statistical Package for the Social Sciences (SPSS ${ }^{\circledR}$ ), assumindo a condição de que as duas amostras (SUS e Mercado) são 
dependentes ou emparelhadas. Segundo Triola (2005, p. 346) "se existe alguma relação de modo que cada valor em uma amostra esteja emparelhado com um valor correspondente na outra amostra, as amostras são dependentes".

Como o cálculo do valor da receita "Mercado", descrito anteriormente, partiu das quantidades de serviços também utilizadas para o cálculo do valor "SUS", considerou-se que essas amostras são emparelhadas.

Aplicou-se o teste para essas duas amostras no perío- do de 2003 a 2005, rejeitando-se a hipótese nula $\left(\mathrm{H}_{\mathrm{o}}\right.$ : O valor médio da Receita SUS $\left(\mu_{1}\right)$ é igual ao valor médio da Receita Mercado $\left(\mu_{2}\right)$ ou HO: $\left.\mu_{1}=\mu_{2}\right)$, em um nível de significância de menos que $1 \%$ (Tabela 3). Ou seja, podese inferir (com praticamente $100 \%$ de segurança) que os valores da receita SUS e da Receita Mercado são estatisticamente diferentes.

Portanto, existe uma diferença estatística significativa entre os valores referenciais do SUS e da FAEPA, ou

Tabela 1 - Comparativo Receita Contábil (SUS) versus Receita Econômica (FAEPA)

\begin{tabular}{|l|c|c|c|c|c|c|}
\hline \multirow{2}{*}{ MÊS } & \multicolumn{2}{|c|}{2003} & 2003 & 2004 & 2004 & 2005 \\
\hline & SUS & MERCADO & SUS & MERCADO & SUS & MERCADO \\
\hline Janeiro & $4.095 .169,64$ & $13.002 .307,07$ & $4.879 .893,43$ & $11.767 .275,90$ & $5.165 .184,09$ & $14.266 .379,20$ \\
\hline Fevereiro & $4.345 .235,60$ & $15.855 .926,10$ & $5.027 .645,89$ & $14.065 .387,25$ & $5.112 .644,59$ & $16.417 .477,62$ \\
\hline Março & $4.590 .740,31$ & $15.548 .444,14$ & $9.533 .152,04$ & $14.171 .774,71$ & $5.834 .411,60$ & $20.152 .329,60$ \\
\hline Abril & $4.626 .828,91$ & $15.923 .550,09$ & $5.447 .148,53$ & $14.393 .142,62$ & $6.004 .302,51$ & $21.327 .860,77$ \\
\hline Maio & $4.839 .447,89$ & $16.361 .419,20$ & $4.579 .305,56$ & $12.545 .956,76$ & $6.014 .464,70$ & $19.857 .190,97$ \\
\hline Junho & $4.417 .968,44$ & $15.045 .280,64$ & $4.705 .376,87$ & $11.494 .120,94$ & $6.384 .359,42$ & $18.359 .582,25$ \\
\hline Julho & $4.761 .943,03$ & $15.223 .871,20$ & $5.408 .671,69$ & $13.397 .330,54$ & $6.553 .184,39$ & $19.212 .902,51$ \\
\hline Agosto & $4.939 .042,84$ & $16.654 .700,13$ & $5.673 .748,04$ & $15.394 .752,12$ & $6.772 .340,76$ & $21.702 .870,64$ \\
\hline Setembro & $4.948 .601,84$ & $16.116 .901,62$ & $5.234 .671,63$ & $14.161 .197,99$ & $6.355 .814,96$ & $20.514 .669,44$ \\
\hline Outubro & $5.222 .821,27$ & $16.874 .336,98$ & $5.561 .482,50$ & $14.740 .422,83$ & $6.480 .378,00$ & $21.315 .811,99$ \\
\hline Novembro & $5.035 .701,29$ & $16.563 .938,87$ & $5.634 .405,10$ & $14.634 .631,06$ & $6.473 .459,89$ & $17.697 .129,48$ \\
\hline Dezembro & $4.748 .972,75$ & $13.725 .948,60$ & $4.916 .244,13$ & $11.583 .554,92$ & $7.338 .595,88$ & $14.437 .793,44$ \\
\hline Total & $56.572 .473,81$ & $186.896 .624,64$ & $66.601 .745,41$ & $162.349 .547,64$ & $74.489 .140,79$ & $225.261 .997,87$ \\
\hline
\end{tabular}

Tabela 2 - Teste de normalidade (Komolgorov-Smirnov): SUS / mercado

\begin{tabular}{|l|l|l|}
\hline \multicolumn{2}{|c|}{ TESTE KOMOLGOROV-SMIRNOV PARA UMA AMOSTRA } & \\
\hline Número de observações & & 36 \\
\hline Parâmetros normais a, b & Média & 10467911 \\
& Desvio padrão & 2589230,5 \\
\hline & Valor absoluto &, 107 \\
\hline Maiores diferenças & Positiva &, 107 \\
\hline Komolgorov-Smirnov Z & Negativa &,- 079 \\
\hline Significância assintótica (Bicaudal) & &, 644 \\
\hline
\end{tabular}

a. A distribuição do teste é normal.

b. Calculados dos dados. 
mercado: em outras palavras, representa o quanto ( $R$ \$) a sociedade pagaria se o HU Público não existisse, pois teriam de recorrer à iniciativa privada.

Seguindo esse raciocínio, se o HU Público não existisse, a comunidade atendida pagaria à iniciativa privada um valor praticamente três vezes maior.

Mas, a diferença entre o valor pago atualmente (SUS) e o valor que ela pagaria (Mercado) ainda não pode ser considerada como uma "economia" feita pela sociedade. Deve-se considerar também, o valor do custo de oportunidade do capital do Estado (Tabelas 3 e 4).

\section{Cálculo do resultado econômico operacional ou lucro operacional}

Os custos utilizados para calcular o Resultado Econômico Operacional ou o Lucro Operacional (LOP) foram exatamente os valores fornecidos pelo hospital. Da atividade de ensino, decorrem diversos fatores com impacto nos custos dos hospitais universitários.

Entretanto, considerando o princípio contábil do conservadorismo, optou-se por não retirar dos Custos Operacionais o efeito incremental pertinente à atividade de ensino, apesar de este estudo não ter avaliado o resultado econômico da atividade específica relacionada ao ensino. Assim, tem-se o Resultado Econômico Operacional (Quadro 3).

\section{Cálculo do VECP e do VEAS pelo HU Público}

Conforme as considerações feitas quanto à apuração dos valores econômicos, foi calculado o valor econômi- co proposto no Quadro 2. As Tabelas 3 e 4 demonstram os resultados apurados para os anos 2003, 2004 e 2005.

A Tabela 4 ilustra o cálculo do Valor Econômico Agregado de Curto Prazo (VECP), obtido pela diferença entre o Resultado Econômico Operacional (1) e o Custo de oportunidade do capital do Estado (2), para os anos de 2003, 2004 e 2005.

Para o cálculo do Custo de oportunidade do capital do Estado (2), de curto prazo, foi realizado um levantamento de todas as Subvenções Estaduais recebidas pelo Hospital nos respectivos anos. Para tanto, recorreu-se ao relatório de atividades do HU Público e aos demonstrativos publicados (vide protocolo do estudo de caso).

Dessa forma, discriminaram-se os investimentos realizados pelo governo em duas categorias: (i) SUS, via ressarcimento pelos serviços prestados pela instituição; e (ii) investimentos em custeio, ou seja, de funcionamento realizados, diretamente, pelo governo do Estado de São Paulo e indiretamente, via Autarquia, no caso Faculdade de Medicina.

Operacionalmente, multiplica-se o investimento realizado pelo governo no período pelo seu respectivo custo, representado pela taxa SELIC. Logo, tem-se o Custo de oportunidade do capital do Estado (2). Assim, Valor Econômico Agregado de Curto Prazo (VECP) representa o que a sociedade pagaria se recorresse ao setor privado (1), caso o HU Público não existisse, deduzido do valor que a sociedade paga (2). Trata-se da prestação de contas do desempenho econômico, até então não realizada pelas instituições do setor público.

Tabela 3 - Teste de diferença de médias (SUS / mercado)

\begin{tabular}{|c|c|c|c|c|c|c|c|c|}
\hline \multicolumn{9}{|c|}{ TESTE PARA AMOSTRAS EMPARELHADAS } \\
\hline \multicolumn{9}{|c|}{ DIFERENÇAS EMPARELHADAS } \\
\hline & \multirow[b]{2}{*}{ Média } & \multirow[b]{2}{*}{ Desvio padrão } & \multirow{2}{*}{$\begin{array}{l}\text { Média do } \\
\text { erro padrão }\end{array}$} & \multicolumn{2}{|c|}{$\begin{array}{l}\text { Intervalo de confiança de } \\
95 \% \text { para a diferença }\end{array}$} & \multirow[b]{2}{*}{$\mathrm{t}$} & \multirow{2}{*}{$\begin{array}{l}\text { Graus de } \\
\text { Liberdade }\end{array}$} & \multirow{2}{*}{$\begin{array}{l}\text { Significância } \\
\text { (Bicaudal) }\end{array}$} \\
\hline & & & & Mínimo & Máximo & & & \\
\hline Pair 1 SUS - Mercado & $-1,0 \mathrm{E}+07$ & 2589230,593 & 431538,4 & $-1,1 \mathrm{E}+07$ & -9591842 & $-24,257$ & 35 &, 000 \\
\hline
\end{tabular}

Quadro 3 - Resultado econômico operacional

Receita Econômica

(-) Custos Operacionais

(-) Despesas Operacionais

(=) Resultado Econômico Operacional (1)
(Receita ao valor de mercado)

(Custo efetivamente incorrido)

(Despesa efetivamente incorrida) 
A Tabela 5 ilustra o cálculo do Valor Econômico Agregado para a Sociedade (VEAS), obtido pela diferença entre o Resultado Econômico Operacional (1) e o Custo de oportunidade do capital do Estado Longo Prazo (3), para os anos de 2003, 2004 e 2005.

Nesse caso, a diferença conceitual entre o VECP (Tabela 4) e o VEAS (Tabela 5) reside no custo de oportunidade para a sociedade (3), agora calculado em função dos investimentos fixos ou de longo prazo e não mais nos investimentos em custeio e ressarcimentos do SUS. Para tanto, considera-se como Investimento Total o Passivo Oneroso (Passivo) e o Patrimônio Líquido (PL), que representa o Investimento Fixo efetivo realizado pelo governo no período.

Assim, existe uma sensível diferença entre os valores apontados por VECP e VEAS. Com a justificativa de verificar a necessidade do cálculo dessas duas medidas de valor e, ao mesmo tempo, aumentar a confiabilidade (em termos analíticos) dos valores por elas gerados, investigou-se se a diferença entre os valores VECP e VEAS era estatisticamente significativa, tal como realizado para os valores das receitas SUS e Mercado.

Acompanhado a Tabela 6, nota-se que, a partir da condição (verificada no SPSS ${ }^{\circledast}$ ) de que essas amostras (VECP e VEAS para os anos de 2003, 2004 e 2005) possuem uma distribuição normal, rejeita-se Ho, ou seja, assume-se que o valor médio do VECP não é igual ao valor médio da VEAS em um nível de significância menor que 1\% (com praticamente $100 \%$ de segurança, Figura 4).

Pode-se, então, assumir que os indicadores VECP e VEAS, embora emparelhados, são estatisticamente diferentes.

E que, portanto, devem-se separar os investimentos de curto prazo (normalmente associados ao custeio das atividades, ao ciclo operacional) dos investimentos de longo prazo (estruturais) no cálculo do valor econômico agregado à sociedade pelo Hospital (ou departamentos), sugerindo a necessidade do uso dessas duas medidas de valor (VECP e VEAS, referenciadas no Quadro 2) de forma concomitante.

\section{Análise dos resultados do cálculo do valor econômico agregado à sociedade (VECP e VEAS) pelo HU Público}

Os valores encontrados pelas medidas VECP e VEAS vão ao encontro da realidade do hospital analisado. Em 2003, foram realizadas 48.548 consultas, para 43.157 no ano de 2005. A evolução do número de internações também reflete o rearranjo operacional proporcionado pelo sistema de referência e contrarreferência: por meio da disponibi-

Tabela 4 - Valor econômico agregado de curto prazo (VECP)

\begin{tabular}{|c|c|c|c|}
\hline VALOR ECONÔMICO AGREGADO DE CURTO PRAZO & 2003 & 2004 & 2005 \\
\hline Receita Econômica & $186.896 .624,64$ & $162.349 .547,64$ & $225.261 .997,87$ \\
\hline (-) Custos Operacionais & $(135.716 .486,31)$ & $(127.960 .853,38)$ & $(160.033 .907,18)$ \\
\hline (-) Despesas Operacionais & $(4.575 .842,64)$ & $(6.005 .027,42)$ & $(13.101 .639,23)$ \\
\hline (=) Resultado Econômico Operacional (1) & $46.604 .295,68$ & $28.383 .666,85$ & $52.126 .451,45$ \\
\hline Ressarcimentos do SUS (União) & $68.645 .295,00$ & $70.120 .000,00$ & $88.940 .836,00$ \\
\hline $\begin{array}{l}\text { (+) Subvenções para Custeio } \\
\text { (Governo do Estado e Autarquia) }\end{array}$ & $119.481 .434,00$ & $142.829 .129,00$ & $165.906 .632,00$ \\
\hline $\begin{array}{l}\text { (=) Investimento Total (SUS + Orçamento) } \\
\text { feito pelo governo na entidade no período }\end{array}$ & $188.126 .729,00$ & $212.949 .129,00$ & $254.847 .468,00$ \\
\hline (x) Taxa SELIC & $23,62 \%$ & $16,19 \%$ & $19,12 \%$ \\
\hline (=) Custo de oportunidade do capital do Estado (2) & $44.426 .127,05$ & $34.485 .336,87$ & $48.714 .093,51$ \\
\hline Resultado Econômico Operacional (1) & $46.604 .295,68$ & $28.383 .666,85$ & $52.126 .451,45$ \\
\hline (-) Custo de oportunidade do capital do Estado (2) & $(44.426 .127,05)$ & $(34.485 .336,87)$ & $(48.714 .093,51)$ \\
\hline (=) Valor Econômico Agregado de Curto Prazo (VECP) & $2.178 .168,63$ & $(6.101 .670,02)$ & $3.412 .357,94$ \\
\hline
\end{tabular}


lidade de um sistema informatizado ligado diretamente ao banco de dados do HU Público. Existe uma previsão da demanda, importante para o dimensionamento e alocação de recursos (medicamentos, material, pessoal etc.).

Ou seja, os pacientes chegam referenciados (daí referência), isto é, indicados por uma Unidade Básica de Saúde (UBS) ou hospital de menor porte ou complexidade. Assim, no HU Público, o número de internações foi de 21.313 em 2003, 19.508 em 2004, e de 20.237 em 2005. Essa redução reforça a maior complexidade dos casos atendidos.
Com esse modelo, o HU Público efetivou-se na assistência médica de alta complexidade no sistema de saúde da região. Sendo assim, tem espaços preservados para o atendimento dos casos mais graves ou que não foram elucidados nas instâncias primárias do SUS: UBS e hospitais de menor porte.

Os valores econômicos calculados nas Tabelas 3 e 4 apresentam os impactos econômicos do novo modelo assistencial do hospital. A prioridade para atendimentos mais complexos fez aumentar o valor econômico do hospital para a sociedade, mesmo com a redução na quanti-

Tabela 5 - Valor econômico agregado para a sociedade (VEAS)

\begin{tabular}{|c|c|c|c|}
\hline VALOR ECONÔMICO AGREGADO PARA A SOCIEDADE & 2003 & 2004 & 2005 \\
\hline Receita Econômica & $186.896 .624,64$ & $162.349 .547,64$ & $225.261 .997,87$ \\
\hline (-) Custos Operacionais & $(135.716 .486,31)$ & $(127.960 .853,38)$ & $(160.033 .907,18)$ \\
\hline (-) Despesas Operacionais & $(4.575 .842,64)$ & $(6.005 .027,42)$ & $(13.101 .639,23)$ \\
\hline (=) Resultado Econômico Operacional (1) & $46.604 .295,68$ & 28.383.666,84 & $52.126 .451,45$ \\
\hline $\begin{array}{l}\text { (=) Investimento Total (Passivo oneroso +PS) } \\
\text { feito pelo governo na entidade no período }\end{array}$ & $38.020 .634,79$ & $50.228 .521,96$ & 71.294.355,96 \\
\hline (x) Taxa SELIC & $23,62 \%$ & $16,19 \%$ & $19,12 \%$ \\
\hline (=) Custo de oportunidade para a Sociedade - LP (3) & $8.978 .572,91$ & $8.134 .090,56$ & $13.627 .916,14$ \\
\hline Resultado Econômico Operacional (1) & $46.604 .295,68$ & $28.383 .666,84$ & $52.126 .451,45$ \\
\hline (-) Custo de oportunidade para a Sociedade - LP (3) & $(8.978 .572,91)$ & $(8.134 .090,56)$ & $(13.627 .916,14)$ \\
\hline (=) Valor Econômico Agregado para a Sociedade (VEAS) & $37.625 .722,78$ & $20.249 .576,29$ & $38.498 .535,31$ \\
\hline
\end{tabular}

Tabela 6 - Teste de normalidade (Komolgorov-Smirnov) (VECP/ VEAS)

TESTE KOMOLGOROV-SMIRNOV PARA UMA AMOSTRA

Número de observações

Parâmetros normais ${ }^{\mathrm{a}, \mathrm{b}}$

Maiores diferenças

Komolgorov-Smirnov Z

Significância assintótica (Bicaudal)

a. A distribuição do teste é normal.

b. Calculados dos dados.
36

Média

2691250

Desvio padrão

431898,9

Valor absoluto

, 137

Positiva

, 117

Negativa
$-, 137$

, 820

,512 
dade de serviços prestados. Isto mostra que a assistência pelo HU Público aos casos de alta complexidade agrega mais valor à sociedade que os casos mais simples atendidos anteriormente.

Outro ponto importante observado nas Tabelas $3 \mathrm{e}$ 4: a consistência do cálculo do valor agregado. Houve uma queda significativa do Valor Econômico Agregado de Curto Prazo (VECP) no ano de 2004 e uma retomada em 2005. Essa queda reflete uma greve dos funcionários ocorrida nesse ano, na qual o hospital ficou dois meses atuando com níveis mínimos de atividade.

\section{SÍNTESE DOS RESULTADOS E CONSIDERAÇÕES}

Como os modelos avaliam as atividades a valor de mercado, a redução no nível de atividade do hospital gerou Valor Econômico Agregado de Curto Prazo negativo, o que significa que o hospital destruiu valor econômico da sociedade nesse período. Então, fica claro como o valor econômico reflete o prejuízo que a sociedade tem quando o HU Público deixa de prestar seu serviço.

Mesmo a redução na taxa SELIC no período de análise (entre 2003 e 2005), que reflete o custo de oportunidade do capital investido pela sociedade, não foi suficiente para fazer com que a instituição agregasse valor.

Essa medida de valor de econômico agregado de curto prazo (VECP) também apontou uma influência significativa do custo de oportunidade dos investimentos fixos para o custeio das atividades do hospital (curto prazo), representados pelas subvenções do governo do Estado e da autarquia, destinadas ao pagamento dos servidores, ou seja, existe uma estrutura operacional instalada e, fundamentalmente, representada pelo número de Médicos contratados e de Leitos disponíveis.

Por sua vez, a medida de valor econômico agregado de longo prazo (VEAS) demonstrou a existência de investimentos fixos (longo prazo) depreciados, que mesmo assim possibilitam a prestação de serviços à sociedade e têm feito com que o hospital agregue valor.

No cálculo da receita econômica, utiliza-se a iniciativa privada como parâmetro para comparação. Em tese, na formação dos valores cobrados pelo setor privado estão embutidos os custos de depreciação pelos investimentos fixos feitos.

Dessa forma, se a sociedade optasse pela iniciativa privada, estaria bancando os investimentos. Isso explica a diferença significativa entre os valores apurados pelas medidas VECP e VEAS. A longo prazo (VEAS), a sociedade está usufruindo a condição de maturidade dos investimentos feitos no HU Público.

Além disso, o Valor Econômico Agregado mostra a eficiência da entidade em prestar o serviço público. Enquanto o superávit apresentado nas demonstrações contábeis foi de R 20 milhões (sem deduzir o custo do capital investido), o valor econômico agregado para a sociedade (já deduzido o custo de oportunidade do capital investido) foi de R 38 milhões. Fica clara a eficiência do hospital como meio de prestação de serviços públicos.

O objetivo deste artigo era o de demonstrar como pode ser mensurado o valor econômico agregado por um Hospital Universitário Público. Assim, foi feita revisão bibliográfica sobre o assunto e foram calculados os valores econômicos, de acordo com a teoria estudada.

O cálculo do valor econômico agregado à sociedade pelo Hospital Universitário Público pode servir como referência para outros estudos.

Porém, as conclusões delineadas neste estudo não podem ser generalizadas a todos os hospitais universitários públicos brasileiros, pois as características culturais da entidade, sua relação com a universidade, o grau de desenvolvimento econômico e social da região etc. são fatores determinantes na condução das políticas assistenciais promovidas.

As medidas de valor propostas para o cálculo do valor econômico agregado à sociedade podem ser aprimoradas

Tabela 7 - Teste de diferença de médias (VECP / VEAS)

\begin{tabular}{|c|c|c|c|c|c|c|c|c|}
\hline \multicolumn{9}{|c|}{ TESTE PARA AMOSTRAS EMPARELHADAS } \\
\hline \multicolumn{9}{|c|}{ DIFERENÇAS EMPARELHADAS } \\
\hline & \multirow[b]{2}{*}{ Média } & \multirow[b]{2}{*}{ Desvio padrão } & \multirow{2}{*}{$\begin{array}{l}\text { Média do } \\
\text { erro padrão }\end{array}$} & \multicolumn{2}{|c|}{$\begin{array}{l}\text { Intervalo de confiança de } \\
95 \% \text { para a diferença }\end{array}$} & \multirow[b]{2}{*}{$\mathrm{t}$} & \multirow{2}{*}{$\begin{array}{l}\text { Graus de } \\
\text { Liberdade }\end{array}$} & \multirow{2}{*}{$\begin{array}{c}\text { Signifi- } \\
\text { cância } \\
\text { (Bicaudal }\end{array}$} \\
\hline & & & & Mínimo & Máximo & & & \\
\hline Pair 1 VECP - VEAS & -2691249 & 431898,89312 & 71983,15 & -2837383 & -2545116 & $-37,387$ & 35 & ,000 \\
\hline
\end{tabular}


com o desenvolvimento de estudos que incorporem variáveis representativas das condições demográficas e de renda da região atendida pelo hospital universitário público.

Igualmente, essas medidas podem ser expandidas para analisar o desempenho dos serviços educacionais e de pesquisa dos hospitais universitários públicos, considerando como direcionadores de valor, por exemplo, produção acadêmica, formação de médicos residentes e implementação de programas de saúde preventiva.

Um último ponto a se destacar é a questão da aproximação da gestão pública e da gestão privada. A entidade privada, por força da concorrência, evoluiu muito em relação às metodologias de avaliação do desempenho. Enquanto isso, a gestão pública, em algumas áreas, fez o caminho inverso.

Muitas vezes, por questões políticas, não existe interesse em mostrar o desempenho, ofuscando a accountability. Cabe então à sociedade cobrar do governo essa transparência em sua gestão. E a academia tem muito a contribuir, especialmente trazendo ferramentas de avaliação de desempenho que aproximem a gestão pública da sociedade.

\section{REFERÊNCIAS}

ALBANO, M. Dívida "estrangula" hospitais universitários federais. FolhaOnline, 08 dez. 2002. Disponível em http://wwwl.folha.uol.com.br/ folha/educacao/ult305ul1911.shtml. Acesso em: 15.06. 2005.

ASSAF NETO, A. Finanças corporativas e valor. São Paulo: Atlas, 2003.

ASSOCIAÇÃO MÉDICA BRASILEIRA (AMB). Disponível em: http://www. amb.org.br/. Acesso em 17.11.2005.

BARBOSA, P. R. Gestão de hospitais públicos: maior autonomia gerencial, melhor performance organizacional com apoio em contratos de gestão. Revista do Serviço Público, v. 120, n. 2, p. 629-643, 1996.

BARROW, M., WAGSTAFF, A. Efficiency measurement in the public sector: an appraisal. Fiscal Studies, v. 10, n. 1, p. 73-97, 1989.

BITTAR, O. J. N. V. Produtividade em hospitais de acordo com alguns indicadores hospitalares. Revista de Saúde Pública, v. 30, n. 1, p. 53-60, 1996.

BOSSERT, T.; LARRANAGA, O.; MEIR, F. R. Descentralización de los sistemas de salud en América Latina. Revista Panamericana de Salud Publica, v. 8, n. 1-2, p. 84-92, 2000.

CAMPOS, G. W. S. Educação médica, hospitais universitários e o Sistema Único de Saúde. Caderno de Saúde Pública, v. 15, n. 1, p. 187-194, 1999.
CARR-HILL, R. Allocating resources to health care: RAWP is dead - long live RAWP. Health Policy, v. 7, n. 13, p. 133-144, 1989.

CECILIO, L. C. de O. O estado como prestador direto da assistência hospitalar. Revista de Administração Pública, v. 33, n. 2, p. 23-37, 1999.

CHERCHIGLIA, M. L.; DALLARI, S. G. Tempo de mudanças: sobrevivência de um hospital público. RAE-eletrônica, v. 5, n. 2, 2006. Disponível em http://www.rae.com.br/eletronica/index.cfm?FuseAction=Artigo\&ID $=3578 \&$ Secao $=$ ARTIGOS $\&$ Volume $=5 \&$ numero $=2 \& A n o=20$. Acesso em 20.03.2006.

CORDEIRO, H. Descentralização, universalidade e equidade nas reformas da saúde. Revista Ciência \& Saúde Coletiva, v. 6, n. 2, p. 319-28, 2001.

DANIELS, N. Equity of access to health care: some conceptual and ethical issues. Milbank Memorial Fund Quarterly, v. 12, n. 60, p. 51-81, 1982.

DATASUS: Banco de dados do Sistema Único de Saúde (SUS). 2005 Disponível em ttp://w3.datasus.gov.br/datasus/datasus.php. Acesso em 20.03.2006.

GOVERNO FEDERAL. 2004. Disponível em htp://www.planobrasil.gov. br. Acesso em 02.11.2005.

HOSPITAIS Universitários e de ensino no Brasil: desafios e soluções. Linha Direta UnB, n. 46, 2002. Disponível em http://www.unb.br/reitor/reitoriainforma/linha_direta/linha_direta 46.htm. Acesso em 15.08.2004.

JARLIER, A; CHARVET-PROTAT, S. Can improving quality decrease hospital costs? International Journal for Quality in Health Care, v. 12, n. 2, p. 125-133, 2000.

LEEDER, S. R. Valuable health: what do we want, and how do we get it? Australian Journal of Public Health, v. 16, n. 2, p. 8-24, 1992.

LIMA-GONÇALVES, E. Estrutura organizacional do hospital moderno. RAE-revista de administração de empresas, v. 38, n. 1, p. 80-90, 1998

LIMA-GONÇALVES, E; ACHÉ, C. A. O Hospital-empresa: do planejamento à conquista do mercado. RAE-revista de administração de empresas, v. 39, n. 1, p. 84-97, 1999.

MACHADO, S; KUCHENBERCKER, R. Desafios e perspectivas futuras dos hospitais universitários no Brasil. Revista Ciência \& Saúde Coletiva, v. 12, n. 4, p. 871-877, 2007.

MAGALHÃES JR, H. M. O desafio de construir e regular redes públicas com integralidade em sistemas privado-dependentes: a experiência de Belo Horizonte. 2006. 211 p. Tese de Doutorado em Ciências Médicas, Faculdade de Ciências Médicas, Universidade de Campinas, Campinas, 2006.

MALIK, A. M. Desenvolvimento de recursos humanos, gerência de qualidade e cultura das organizações de saúde. RAE-revista de administração de empresas, v. 32, n. 3, p. 32-41, 1992.

MALIK, A. M; TELES, J. P. Hospitais e programas de qualidade no Estado de São Paulo. RAE-revista de administração de empresas, v. 4l, n. 3, p. $51-59,2001$ 
MALTA, D. C; CECÍlIO, L. C. O; MERHY, E. E; FRANCO, T. B; JORGE, A. O; COSTA, M. A. Perspectivas da regulação na saúde suplementar frente aos modelos assistenciais praticados. Revista Ciência \& Saúde Coletiva, v. 9, n. 4, p. 433-44, 2004.

MARINHO, A. Estudo de eficiência em alguns hospitais públicos e privados com a geração de rankings. Revista de Administração Pública, v. 32, n. 6, p. 145-158, 1998.

MARTINS, G. A; THEÓPHILO, C. R. Metodologia da investigação científica para ciências Sociais Aplicadas. São Paulo: Atlas, 2007.

MATOS, C. A.; POMPEU, J. C. Onde estão os contratos? Análise da relação entre os prestadores de serviços privados e o SUS. Revista de Ciência E Saúde Coletiva, v. 8, n. 2, p. 629-644, 2003.

MEDICI, A. C. Hospitais universitários: passado, presente e futuro. Revista da Associação Medica Brasileira, v. 47, n. 2, p. 149-156, 2001.

O MAPA dos hospitais: empreendimentos privados perdem espaço. Gazeta Mercantil. São Paulo, p. A10, 27 jun. 2006.

OLAK, P. A. Bases para a eficácia na aplicação do contrato de gestão nas organizações sociais brasileiras. 2000. 234 p. Tese de Doutorado em Ciências Contábeis, Faculdade de Economia, Administração e Contabilidade, Universidade de São Paulo, São Paulo, 2000.

PORTELA, M. C; LIMA, S; BARBOSA, P; VASCONCELLOS, M. M; UGÁ M. A; GERSCHMAN, S. Caracterização assistencial dos hospitais filantrópicos no Brasil. Revista de Saúde Pública, v. 38, n. 4, p. 811-818, 2004.
SANTOS, F. P; MERHY, E. A regulação pública da saúde no estado brasileiro: uma revisão. Revista Interface. Botucatu, v. 10, n. 19, p. 25-41, 2006

SILVA, E. P; COSTA, P. S; TIBÉRIO, C. S. B. Gestão estratégica de custos: estudo de caso aplicado a hospitais universitários. In: CONGRESSO INTERNACIONAL DE CUSTOS, 8, 2003, Montevidéu. Anais. Montevidéu: 2003. CD-ROM

SLOMSKI, V. Mensuração do resultado econômico em entidades públicas: uma proposta. 1996. 82 p. Dissertação Mestrado em Ciências Contábeis, Faculdade de Economia, Administração e Contabilidade, Universidade de São Paulo, São Paulo, 1996.

SLOMSKI, V. Manual de contabilidade pública: um enfoque na contabilidade municipal. 2. ed. São Paulo: Atlas, 2003.

SLOMSKI, V. Controladoria e governança na gestão pública. São Paulo: Atlas, 2005.

TABELA SUS - Tabelas de coeficientes de honorários do ministério da saúde (MS). 2005. Disponível em http://www.calcmed.com.br/tabelasnet/ tabelas_convenios.asp. Acesso em 03.03.2006.

TRIOLA, M. F. Introdução à estatística. 9. ed. Rio de Janeiro: LTC, 2005.

VERGARA, C. El contexto de las reformas del sector de la salud. PanAmer Journal Public Health, v. 8, n. 1, p. 7-12, 2000.

YIN, R. K. Estudo de caso: planejamento e método. 3. ed. Porto Alegre: Bookman, 2005 